\title{
THE DEVELOPMENT OF STUDENTS' ALGORITHMIC COMPETENCE BY MEANS OF ELECTRONIC LEARNING RESOURCES
}

\author{
Evgenia V. Baranova ${ }^{1}$, Irina V. Simonova ${ }^{1}$, Mikhail I. Bocharov ${ }^{2}$ and Victoria V. Zabolotnaia ${ }^{3}$ \\ ${ }^{1}$ Herzen State Pedagogical University of Russia \\ Moika River, 48, St. Petersburg, 191186, Russia \\ ${ }^{2}$ Moscow City University \\ Vtoroy Selskohoziajstvenny proezd, 4, Moscow, 129226, Russia \\ ${ }^{3}$ Transnistrian State University named after T.G. Shevchenko \\ Gagarina 12, Rybnita, 5500, Moldova
}

\begin{abstract}
The problem of development of algorithmic competence of students - future Computer Science teachers as a component of information competence is investigated. The aim of the study is to identify the conditions for effective algorithmization and programming learning, involving a modular representation of the content, blended learning, allocated in accordance with the B. Bloom's taxonomy classes of problems in Computer Science and Methods of its Teaching and the use of electronic learning resources. This paper specifies the concept of algorithmic competence of university students - students' readiness to design algorithms and programs, their use in professional activities in the process of Computer Science teaching, electronic learning resources (ELR) design, self-education in the field of Computer Science. Classes of problems for algorithmic competence development in accordance with B. Bloom's taxonomy (knowledge, comprehension, application, analysis, synthesis and evaluation) are identified. Classes of problems correspond to ELR of a certain structure and content. The efficiency of ELR use in students' algorithmic competence development is statistically confirmed.
\end{abstract}

\section{KEYWORDS}

Algorithmic Competence, B. Bloom's Taxonomy, Computer Science Teacher Training, Blended Learning, Electronic Learning Resources

\section{INTRODUCTION}

The development of blended and electronic learning create the prerequisites for improving the efficiency of training, strengthening, which is of crucial importance for the younger generation, motivation, suggest the necessity to change the ways of working with information. The aim of the study is to identify approaches to the development of algorithmic component of information technology competence of students, future Computer Science teachers. We understand algorithmic competence as the readiness of students to design algorithms and programs, their use in professional activities in the process of Computer Science teaching, electronic learning resources (ELR) design, self-education in the Computer Science field. The development of algorithmic competence in the training of teachers is carried out on a staged basis in various modules of the educational program. The article considers two major modules "Foundations of Computer Science and Programming Techniques" and "Theories and Methods of Computer Science teaching at school". The content of the first module is aimed at the formation of students' theoretical knowledge in the field of Computer Science and algorithmic competence development. The content of the methodical module is aimed at the development of methodical competence of the future Computer Science teacher. We also reveal the system of concepts of General methods of teaching taking into account interdisciplinary connections of Pedagogy and Psychology with the subject "Computer science". Recent changes in educational are closely connected with the introduction of social media in the learning process (Thoma, Hutchison, Johnson, Johnson, Stromer, 2017). 
In-service teachers and academic researchers investigate the questions of media literacy (Velasquez, Mier, Rivera, Marin-Gutierrez, 2017), and the connection between students' engagement into media environment, their motivation (Zylka, Christoph, Kroehne, Hartig, Goldhammer, 2015) and progress (Pounaki, Givi, Fahimnia, 2017).

The main means of algorithmic competence development, according to the authors, is a system of problems in Computer Science and Methods of its Teaching. The system of problems is developed by the authors and is based on the B. Bloom's taxonomy of pedagogical objectives. According to B. Bloom, the taxonomy covering the cognitive domain includes six categories of objectives: knowledge, comprehension, application, analysis, synthesis, and evaluation (Bloom, B. S.; Engelhart, M. D.; Furst, E. J.; Hill, W. H.; Krathwohl, D. R., 1956). Bloom's taxonomy can help assessment in class, as well as assignment development to exercise student's learning in all orders of thinking, including aspects of information searching (Jansen B., Booth D., Smith B., 2009).

The article describes sample problems of the selected modules and corresponding electronic learning resources. The results of the pedagogical experiment prove the effectiveness of ELR for students' algorithmic competence development.

\section{RESULTS}

The research and practical experience in the implementation of Computer Science teachers' training showed the advantage of modular and blended learning. This approach contributes to a flexible system of training, ensures the implementation of individual educational routes and takes into account information technology development. The analysis of various studies shows (.Harin Sellahewa. 2015; Phil Maguire, Rebecca Maguire \& Robert Kelly, 2017; Baranova E.V. \& Simonova I.V. , 2018.) the relevance of the design of educational learning materials for blended learning implementation, including ELR. This approach will allow to vary the forms of blended learning: online study mode, "flipped classes", etc.

The designed model of training is aimed at students' algorithmic competence development and is based on the B. Bloom's taxonomy of pedagogical objectives. This determines the logic of the formation of classes of problems, the readiness to their solving develops in students in the direction from reproductive activity to partly searching and researching. The structure, content and functional of ELR should correspond to the selected classes of problems. The use of ELR provides an opportunity to individualize the rhythm of learning, its place and time. The inclusion of resources in the LMS ensures ELR systematization, the ability to manage training activities, both in the classroom and in the online study mode, allows teachers to carry out tutoring, implement group discussion of tasks to perform. The ELR system allows each student to determine his initial level of algorithmic competence development and build a comprehended individual educational path.

Hereunder we are going to describe the developed by the authors content, sample problems, ELR aimed at students' algorithmic competence development.

\subsection{Module "Foundations of Computer Science and Programming Techniques"}

The module content is aimed at the formation of students' theoretical knowledge in the field of Computer science and the development of algorithmic competence. Students study the concepts of the Theory of Algorithms, Mathematical Logic, Formal Languages and Grammars, Relational Algebra, Information Theory, etc. The module implements interdisciplinary connections with the mathematical module, which studies the mathematical apparatus that forms the basis of Theoretical Computer Science.

The development of algorithmic competence is carried out in the disciplines devoted to the study of modern programming paradigms and involves students' mastery of algorithmic and programming methods. Students form knowledge of basic concepts, principles and methods of programming, on the basis of which they develop the ability to design information models, algorithms, data structures, databases, computer programs, information systems and web resources for solving by means of information technology problems from various fields, including the field of future professional teaching activities.

The study of basic concepts, principles, algorithms of compilation theory contributes to the formation of students' systematic understanding of the sources of syntax errors and skills to develop syntactically correct programs. 
The peculiarity of the discipline is the need for individualization of learning, taking into account different competence levels of students in the programming field: more than $50 \%$ of students do not have or have a vague notion of this type of activity, only $10 \%$ of students usually have notion of programming and are ready to successfully solve complex problems.

Conditions for the formation of individual educational routes of students are provided with a set of sample problems of different complexity levels and electronic learning resources presented in LMS Moodle. Table 1 presents module sample problems and corresponding ELR associated with the B. Bloom's categories.

Table 1. Sample problems and electronic learning resources

\begin{tabular}{|l|l|l|}
\hline \multicolumn{2}{|c|}{ Module "Foundations of Computer Science and Programming Techniques" } \\
categories & $\begin{array}{l}\text { Computer Science sample problems } \\
\text { in accordance with pedagogic } \\
\text { objectives }\end{array}$ & $\begin{array}{l}\text { Electronic learning recourses to achieve } \\
\text { pedagogic objectives }\end{array}$ \\
\hline knowledge & $\begin{array}{l}\text { performing basic operations with data } \\
\text { presented by various structures; }\end{array}$ & $\begin{array}{l}\text { "Data structure" containing a description } \\
\text { of data structures, basic access operations, } \\
\text { examples that illustrate ways of access and } \\
\text { results of operations; }\end{array}$ \\
\hline $\begin{array}{l}\text { comprehension } \\
\text { application }\end{array}$ & $\begin{array}{l}\text { design of algorithms (computational) } \\
\text { and programs based on the known } \\
\text { mathematical apparatus; } \\
\text { design of algorithms and programs } \\
\text { modeling phenomena, processes, } \\
\text { behavior of objects from different } \\
\text { areas; }\end{array}$ & $\begin{array}{l}\text { "Processing algorithms of data structures", } \\
\text { containing a brief description of basic data } \\
\text { processing algorithms presented in } \\
\text { different structures, interactive demos, } \\
\text { self-assessment questions; }\end{array}$ \\
\hline $\begin{array}{l}\text { analysis } \\
\text { synthesis } \\
\text { evaluation }\end{array}$ & $\begin{array}{l}\text { design of algorithms and programs for } \\
\text { the analysis of data presented in } \\
\text { various structures and for the formation } \\
\text { of data according to a given scheme; } \\
\text { design of multi-module programs for } \\
\text { solving educational and professional } \\
\text { problems related to future professional } \\
\text { activities }\end{array}$ & $\begin{array}{l}\text { "Information systems and web resources" } \\
\text { containing a brief description of design } \\
\text { stages, examples of implementation stages } \\
\text { in the form of ready-made applications; the } \\
\text { integrated resource "Syntax analyzer" } \\
\text { aimed at the development of students' } \\
\text { concepts and algorithms of Theoretical } \\
\text { Computer Science }\end{array}$ \\
\hline
\end{tabular}

\subsubsection{Sample Problems for Students}

The achievement of learning objectives is carried out by using a system of sample problems designed to develop students' algorithmic competence, including the readiness to describe and create data structures of different complexity levels, to develop and implement algorithms for solving problems from different fields. The first type of problems involves performing basic data operations represented by various structures: arrays, lists, records, object classes, database tables, etc. To solve these problems, students should know the appropriate syntactic structures, the results of the execution, including the control structures of the programming language under studies. For example, when learning object-oriented paradigm (OOP) programming languages, the central data structure is object class. To solve the problems students should know the basic principles of OOP (encapsulation, inheritance, polymorphism), class structure, ways of description and access to the fields and methods of the class.

The problems of the second type are focused on identifying the formation of algorithmic competence at the level of comprehension and involve the design of computational algorithms and programs based on the known mathematical apparatus. These are, for example, approximate calculations, calculation of series sums, matrix processing, calculation of geometric objects parameters, etc. At this stage students should be ready to interpret the mathematical module, implement a "translation" from the language of Mathematics to the language of Computer Science.

The problems of the third type involve the design of algorithms and programs that simulate phenomena, processes, behavior of objects from various fields. When solving such problems, the formation of algorithmic competence at the level of application, the readiness of students to solve problems in new situations based on known facts, models and rules are verified. This type includes software implementation of simple models 
describing phenomena from various spheres of knowledge, science and technology, the design of fragments of game situations, etc.

At the next, fourth stage, the readiness to analyze the data, to identify the relationship of the data elements, to determine the principles of data organization is formed. The problems of the fourth type include the design of algorithms and programs for analyzing data presented in various structures, and the formation of data according to a specified scheme: algorithms for searching and sorting, creation of object classes with a specified behavior, creation by means of SQL language of related data sets according to a specified scheme.

The synthesis category in Bloom's taxonomy of pedagogic objectives involves the ability to combine elements to produce a whole that is a novel, includes the design of the action plan, the production of a new product. When teaching algorithmization and programming with such a new product, the result of educational activities of students is a computer program. The problems of the fifth type involve the development of multi-modular computer programs, including those for solving educational and professional problems.

With regard to the training of future teachers in the field of Computer Science, it can be electronic learning resources on various topics of school subjects, information systems and web resources for the organization and management of the educational process, testing systems, etc. It is assumed that the sequence of actions of students in the process of information systems design is close to the stages of the life cycle and includes the analysis of the subject area, design, software implementation, testing.

\subsubsection{Electronic Learning Recourses}

For mastering the module a system of electronic learning resources has been designed to improve the efficiency of students' learning the content of the module and achieve learning objectives. The resource "Data structure" contains a systematic description of the studied data structures, basic operations of access to the elements of data structures, examples, illustrating the ways to access and the results of operations. Depending on the studied data structures programming language operators of the selected paradigm, SQL statements, etc. are described. The resource contains tasks of a reproductive nature: to describe the structure representing the data of a specified type, the object class performing a certain functional, the structure of related tables representing the abstraction of some subject area.

The resource "Processing algorithms of data structures" contains a brief description of the basic data processing algorithms presented in various structures, interactive demos - software applications that simulate the operation of algorithms. Such computer models provide a visual display of the algorithms operation for various data sets, allow students on the basis of experiments with different data sets to understand the essence of algorithms. For example, to evaluate the effectiveness of sorting methods, to understand the peculiarities of the execution of statements over the data of the database, to learn how to understand the results of executing complex queries of the SQL language, etc. The included in the resource tasks involve the modification of the considered algorithms for use in the new environment.

The electronic learning resource "Information systems and web resources" is used at the final stage of learning and is aimed at developing students' readiness for independent design of algorithms and programs that implement the specified functional. The resource contains a brief description of the design stages including design of specifications, information model, database structure, software implementation, testing. Professionally performed examples of software applications will help students learn how to analyze the subject area, create their own software products and evaluate their quality.

The integrated electronic learning resource "Syntax analyzer" developed by the following authors (Baranova E. V., Elizarova I. K., 2014), includes several software modules representing important concepts and algorithms of Theoretical Computer Science. First of all, these are models of compiler components: lexis and syntax analyzers, code generator. Working with models, students learn methods of analysis and syntax parsing of chains of formal grammars that describe the sentences of the programming language. Mastering compilation techniques allows students to learn how to design syntactically correct programs. The models use complex data structures to represent the components of formal grammars, trees, graphs. Students learn to analyze algorithms of Theoretical Computer Science, evaluate their effectiveness, "predict" the results of algorithms for different data sets. The resource is of interdisciplinary nature. It is also used in learning process of the mathematical module for mastering various concepts of Discrete Mathematics and methodical module as a tool for teaching Computer Science in the profession-oriented school. 
The described system of problems and electronic learning resources is used during the whole period of training of students in the field of algorithmization and programming. By the end of training, the level of algorithmic competence formation in students allows them to independently analyze the subject area, design data structures and algorithms, create a new software product, evaluate its quality. The most capable and motivated students perform final qualification work on the creation and use of electronic learning resources in the educational process.

\subsection{Module "Theories and Methods of Computer Science Teaching at School"}

The module content is aimed at the development of methodological competence of the future Computer Science teacher, reveals the system of concepts of teaching methods taking into account interdisciplinary connections with the module "Foundations of Computer Science and Programming Techniques" as well as Pedagogy and Psychology. It describes the stages of content development of the school subject "Computer Science" in connection with the development of the science of information and information processes, the computer as a universal means of information processing, software. The content highlights the concept of "information", "algorithm", "model" and problem classes which solving requires comprehension and application of these concepts. Classifications, visual illustrations and demonstrations, schemes, computer models and presentations are used. The types of problems of the school subject "Computer Science" in which the major content line is "Algorithmization and programming" are considered. Methods and techniques, forms and means of education aimed at improving the efficiency of pupils' mastering the educational material are discussed.

Table 2. Sample problems and electronic learning resources

\begin{tabular}{|c|c|c|}
\hline \multicolumn{3}{|c|}{ Module "Theories and methods of Computer Science teaching at school" } \\
\hline $\begin{array}{l}\text { B. Bloom's } \\
\text { categories }\end{array}$ & $\begin{array}{l}\text { Problems of Methods of Computer Science } \\
\text { teaching at school in accordance with } \\
\text { pedagogic objectives }\end{array}$ & $\begin{array}{l}\text { Electronic learning recourses to } \\
\text { achieve pedagogic objectives }\end{array}$ \\
\hline $\begin{array}{l}\text { knowledge } \\
\text { comprehension } \\
\text { analysis }\end{array}$ & $\begin{array}{l}\text { Knowledge formation about basic } \\
\text { peculiarities of Computer Science teaching at } \\
\text { school, the structure and functions of the } \\
\text { methodical system of education: objectives, } \\
\text { content, forms, methods, teaching techniques. }\end{array}$ & $\begin{array}{l}\text { "Methodical system of Computer } \\
\text { Science teaching at school" contains } \\
\text { texts of lectures, scientific articles, } \\
\text { authors of textbooks of Computer } \\
\text { Science for school etc. }\end{array}$ \\
\hline $\begin{array}{l}\text { comprehension } \\
\text { application } \\
\text { analysis }\end{array}$ & $\begin{array}{l}\text { Formation of skills to describe plans and notes } \\
\text { of Computer Science lessons and to explain } \\
\text { problem solving using schemes, drawings, } \\
\text { computer models; to analyze methodical } \\
\text { materials, lessons of teachers. }\end{array}$ & $\begin{array}{l}\text { "Educational learning materials for the } \\
\text { Computer Science lesson at school" } \\
\text { contains examples of lesson plans of } \\
\text { Computer Science teachers, links to } \\
\text { video lessons etc. }\end{array}$ \\
\hline $\begin{array}{l}\text { analysis } \\
\text { synthesis } \\
\text { evaluation }\end{array}$ & $\begin{array}{l}\text { Formation of skills to adapt and create sets of } \\
\text { educational problems for Computer Science } \\
\text { lessons, tasks and tests using IT tools; to make } \\
\text { a plan and to test the prepared materials with } \\
\text { pupils; to participate in discussions. }\end{array}$ & $\begin{array}{l}\text { "Network services for creating } \\
\text { multimedia educational content" } \\
\text { contains detailed instructions for } \\
\text { creating graphic, animations, } \\
\text { processing of audio and video objects. }\end{array}$ \\
\hline
\end{tabular}

\subsubsection{Sample Problems for Students}

Methodical competence development of the future Computer Science teacher involves learning of a set of definitions of major concepts revealing the structure and functions of the methodical system of education: objectives, content, forms, methods, means of teaching and knowledge of basic peculiarities of teaching Computer Science at school, knowledge of concepts and sample problems of the school subject at all levels of school education: primary, secondary, senior. In the course of training to achieve this objective the tasks that contribute to the memorization and comprehension of the logical relationship of the major concepts are used. The tasks involve the construction of logical schemes of concepts within one or more topics in accordance with the textbook material of secondary and senior school, self-construction of working definitions of the concepts "computer", "information", "algorithm", "model", etc. The result of the tasks fulfilling is required to be done with the use of computer tools: logical structure editors, text and table editor. 
The leading activity of the Computer Science teacher is planning of the content of training for the entire period of secondary and senior school, making up of educational and thematic plans for the semester and lesson plans. Sample problems for teaching students this activity are making up a thematic plan on the subject of "Computer Science" for one semester (term); creation of a technological map in support of this plan for the organization of individual educational route of pupils; methods of teaching necessary for the lesson; analysis of video lessons of Computer Science teachers according to the given criteria; own judgment of the achieved lesson objectives, of the quality of teaching tools used, and of methods of pupils' motivating. Such skills are formed in the design process of sets of differentiated tasks for pupils. The future teacher should be able to design and describe the plan and scenario of the network discussion dedicated to actual problems of Computer Science teaching at school, motivation to study modern Computer Science directions, behavior ethics in network communities, etc.

\subsubsection{Electronic Learning Resources}

Electronic learning resources have been developed to support students' independent work and provide individual educational routes for mastering the module material. The resources include systematized theoretical material on topics and presentations focusing on the major aspects of the topic, conclusions, questions and tasks for self-reflection, and tests. Students' practical activity in mastering the subject is supported by laboratory work. The resources are implemented in LMS Moodle.

The resource "Methodical system of Computer Science teaching at school" contains lectures, scientific articles on the methods of Computer Science teaching, articles with the concepts of authors of Computer Science textbooks for school, videos with speeches of scientists and practitioners at thematic conferences, links to video Computer Science lessons, implemented in various conditions of equipping with IT tools and pupils' needs using various pedagogical technologies, bibliography to be studied by students and links to sources, solving problems examples. These materials can be used to perform sample tasks, the list of which is presented in the resource.

The resource "Educational learning materials for the Computer Science lesson at school" contains examples of Computer Science teachers' lesson plans, links to video lessons with an explanation of how to solve complex problems, links to Internet resources with relevant information about new methods and means of Computer Science teaching at school, a set of computer presentations for lessons dedicated to certain topics, a set of computer models in support of solving cross-subject problems, analysis examples of Computer Science lessons according to specified criteria as well as examples of doing the tasks by students of previous years of study.

The resource "Network services for creating multimedia educational content" contains detailed instructions for creating graphic illustrations, animations, processing of audio and video objects, using freely distributed network services, examples of objects created by students of previous years of study, examples of their use in Computer Science lessons, test tasks for each topic for self-reflection, tasks for independent work. The resource is implemented as a web-site with free access and it is used by students throughout the whole period of training to create educational learning materials for lessons: video fragments of lessons, animated videos explaining the training material, infographics and graphic illustrations for lessons (Simonova I., Ustiugova T., Yakovleva O., 2017).

\section{EXPERIMENT}

Two groups of students of the 2-4 courses, trained in the study field of Teacher education, specialization "Computer Science and Information Technologies in Education", took part in the experiment to assess students' readiness to solve the allocated classes of the problems aimed at algorithmic competence development. The control group consisted of 48, while the experimental group of 52 students.

Before the experiment both groups received initial training in Computer Science and Teaching Methods. At the beginning of the 2nd course, both groups had to solve problems of Computer Science and Methodology, focused on the achievement of various categories of achievement of B. Bloom's pedagogic objectives. Table 3 presents the results of the tasks performed by the students of the control and experimental groups. The analysis of the results (Table 3) shows that there were no significant differences between the 
readiness levels of students of both groups to solve sample problems. It should be noted that the problems related to the analysis, synthesis and evaluation of data cause great difficulties for students.

Further training in the experimental group was carried out in the form of blended learning and was based on the application of the described ELR classes. ELRs were not used in the control group. After the modules study completion the final test was carried out, including the same tasks for both groups. The tasks of the control group were aimed at checking the achievement of B. Bloom's pedagogic objectives.

Table 3. Experimental data on the development of students' readiness to solve classes of problems

\begin{tabular}{|l|c|c|c|c|}
\hline \multicolumn{1}{|c|}{$\begin{array}{c}\text { Percentage of students } \\
\text { managing to } \\
\text { solve the } \\
\text { problems }\end{array}$} & \multicolumn{2}{|c|}{ Before the experiment } & \multicolumn{2}{c|}{ After the experiment } \\
\cline { 2 - 5 } $\begin{array}{l}\text { B. Bloom's } \\
\text { categories }\end{array}$ & Control group & $\begin{array}{c}\text { Experimental } \\
\text { group }\end{array}$ & Control group & $\begin{array}{c}\text { Experimental } \\
\text { group }\end{array}$ \\
\hline Knowledge & 0,7708 & 0,6731 & 0,6667 & 0,9615 \\
\hline $\begin{array}{l}\text { Comprehension and } \\
\text { application }\end{array}$ & 0,8125 & 0,8269 & 0,5417 & 0,7692 \\
\hline Analysis & 0,5625 & 0,6538 & 0,5625 & 0,8462 \\
\hline Synthesis and evaluation & 0,3125 & 0,2692 & 0,3333 & 0,5192 \\
\hline
\end{tabular}

The analysis of the results of the final test (Table 3) showed that the results to achieve all pedagogic objectives in the control and experimental group increased. The increment in the experimental group is significantly higher. On the basis of the data given in Table 3 we obtained the following Fisher's ration test (F-test) values which are presented in Table 4 that shows differences in students' readiness to solve problems in Computer Science and Methodology focused on achieving different B. Bloom's categories between the experimental and control groups before and after the experiment.

Table 4. Fisher' ratio test value for assessing differences in students' readiness to solve classes of problems between the experimental and control groups

\begin{tabular}{|l|c|c|}
\hline \multirow{4}{*}{\multicolumn{1}{|c|}{ B. Bloom's categories }} & \multicolumn{2}{|c|}{$\begin{array}{c}\text { Fisher ratio test value } \\
(\varphi-\text { Fisher's angular transformation })\end{array}$} \\
\cline { 2 - 3 } & Differences between the experimental and control groups \\
\cline { 2 - 3 } & Before the experiment & After the experiment \\
\hline Knowledge & 1,0939 & 4,1775 \\
\hline Comprehension and application & 0,1875 & 2,4240 \\
\hline Analysis & 0,9364 & 3,1942 \\
\hline Synthesis and evaluation & 0,4763 & 1,8900 \\
\hline
\end{tabular}

The critical Fisher's ratio test (F-test) value for $1 \%$ of the significance level $\varphi_{\text {cr }}=2,31$ and for $5 \%$ of the significance level $\varphi_{\mathrm{cr}}=1,64$. Before the experiment there were no statistically significant differences in all four categories of the studied features in the control and experimental groups at the specified significance level, since all empirical Fisher's ratio test values before the experiment were lower than the critical value.

The value of the Fisher's angular transformation after the experiment is higher than the critical value equal to about 2.31 to achieve the first three pedagogic objectives and higher than the critical value equal to 1.64 for the fourth objective.

Together with the fact that before the experiment there were no statistically significant differences in the control groups, and after the experiment such statistically significant differences appeared, we can claim that with a probability of $99 \%$ statistically significant differences in the students' training after the experiment were established for the categories: knowledge, comprehension and application, analysis, and with a probability of $95 \%$ statistically significant differences in the students' training after the experiment were established for the category - synthesis and evaluation. 


\section{CONCLUSION}

The present study showed that the development of algorithmic competence of future teachers of Computer Science is contributed by:

- the content presented in the modular structure and implemented in a mixed form,

- classes of problems in Computer Science and Methods of its Teaching focused on students' achieving of the pedagogic objectives in B. Bloom's taxonomy,

- the system of electronic learning resources, which structure and content correspond to the selected classes of problems in Computer Science.

The directions of the research development are possible with the transfer of the proposed approach to other modules of Computer Science teachers training as well as to Computer Science training of specialists of other spheres.

\section{REFERENCES}

Baranova E. V., Elizarova I. K., 2014. Svidelel'stvo o gosudarstvennoj registratsii programmy dlja EVM «Sintaksicheskij analizator» ot 9 ijunja $2014 \mathrm{~g}$.

Baranova E.V. \& Simonova I.V., 2018. The development of professional competencies in the bachelor-level pedagogical training through digital learning in the field of informatics. Izvestia: Herzen University Journal of Humanities \& Sciences, 190, PP. 116-124

Bloom, B. S.; Engelhart, M. D.; Furst, E. J.; Hill, W. H.; Krathwohl, D. R., 1956. Taxonomy of educational objectives: The classification of educational goals. Handbook I: Cognitive domain. New York: David McKay Company.

Harin Sellahewa. 2015. Using an Online Student Response System in Small Group Teaching: A Pilot Study. Innovation in Teaching and Learning in Information and Computer Sciences 10: 38-23.

Jansen B., Booth D., Smith B., 2009. Using the taxonomy of cognitive learning to model online searching, Information Processing \& Management 45 (6), 643-663

Phil Maguire, Rebecca Maguire \& Robert Kelly, 2017. Using automatic machine assessment to teach computer programming 27: 197-214.

Thoma, J., Hutchison, A., Johnson, D., Johnson, K., Stromer, E., 2017. Planning for Technology Integration in a Professional Learning Community. Reading Teacher, 71(2), 167-175.

Simonova I., Ustiugova T., Yakovleva O., 2017. The Impact of Online Services on Developing Students' Media Competence. International Journal of Research in E-learning, Vol. 3 (2), 2017. - PP.35-48

Zylka, J., Christoph, G., Kroehne, U., Hartig, J., Goldhammer, F., 2015. Moving beyond cognitive elements of ICT literacy: First evidence on the structure of ICT engagement. Computers in Human Behavior, 53, 149-160. 